\title{
ANATOMICAL STUDY OF THE RETINAL CIRCULATION*
}

\author{
BY \\ JULES FRANÇOIS
}

From the Ophthalmological Clinic of the University of Ghent, Belgium

THE retinal circulation, and, in particular, the capillaries, have been studied after the injection of Indian ink into the central retinal artery. These researches were undertaken for a double purpose; firstly to verify that the retinal circulation is really terminal, and secondly to see if a horizontal vascular raphé exists between the macula and the temporal periphery analogous with that of the nerve fibres; in other words, to ascertain whether the circulation of the superior part of the temporal half of the retina is independent from that of the inferior part.

Our technique is quite simple. After opening the skull and trephining the optic canal, in addition to the globe and the optic nerve (as far as the chiasma), the orbital contents and the perichiasmal tissues are removed, including the fifth bend of the internal carotid. Through this is introduced a fine cannula, which is made to penetrate first into the ophthalmic artery, and then into the central artery of the retina. After irrigation with distilled water, Indian ink is injected very slowly and with an even pressure.

The following conclusions have been reached:

(1) There exists, in the retina, a dense, complex, tortuous, and irregular capillary network. There is clearly distinguishable a superficial net and a deep net which anastomose freely (Fig. 7).

(2) The capillary net is much closer and denser at the posterior pole than at the periphery of the retina (Figs 1,2 , and 3 ). Its density progressively diminishes from the centre towards the periphery, as do the arterial and venous networks.

(3) Contrary to what is observed in certain animals, for example the rabbit (Fig. 4), the retinal circulation in man is truly terminal (Figs 2 and 3); at the periphery, as at any other area of the retina, no direct communication between an arteriole and a venule may be seen; the junction is effected only through the capillary network.

(4) The circulation in the superior part and that in the inferior part of the temporal half of the retina are not independent. On the contrary, the

* Received for publication July 23, 1951. 


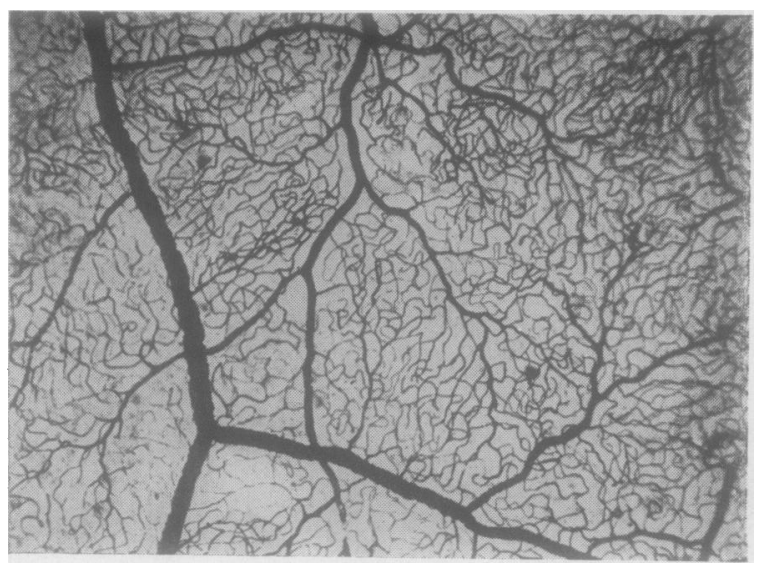

Fig. 1.-Vascular network of the retina at the posterior pole. $\times 45$.

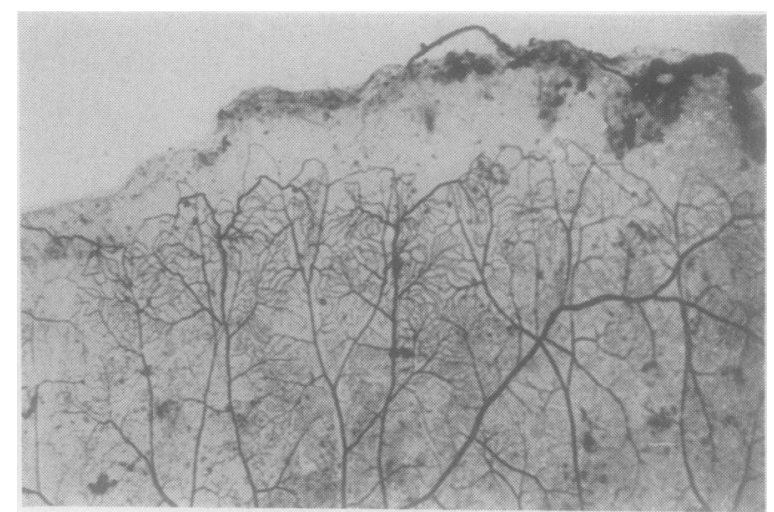

Fig. 2.-Vascular network of the retina at the periphery. $\times 10.5$.

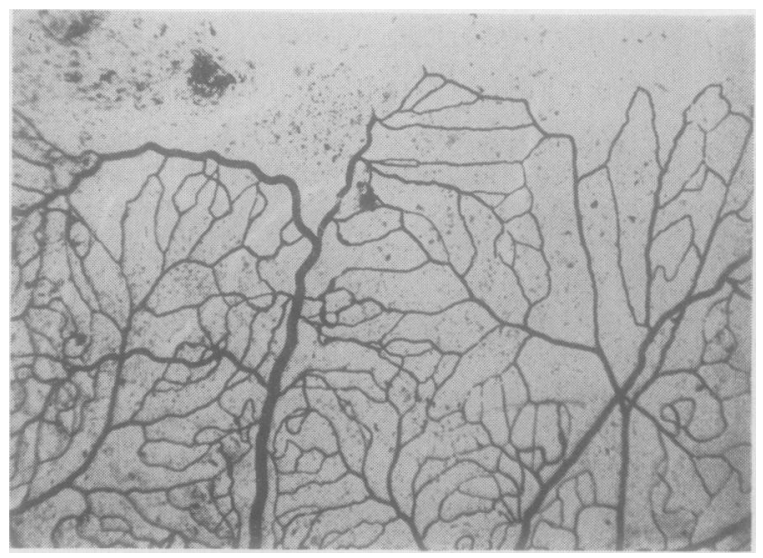

Fig. 3.- Vascular network of the retina at the periphery. $\times 45$. 


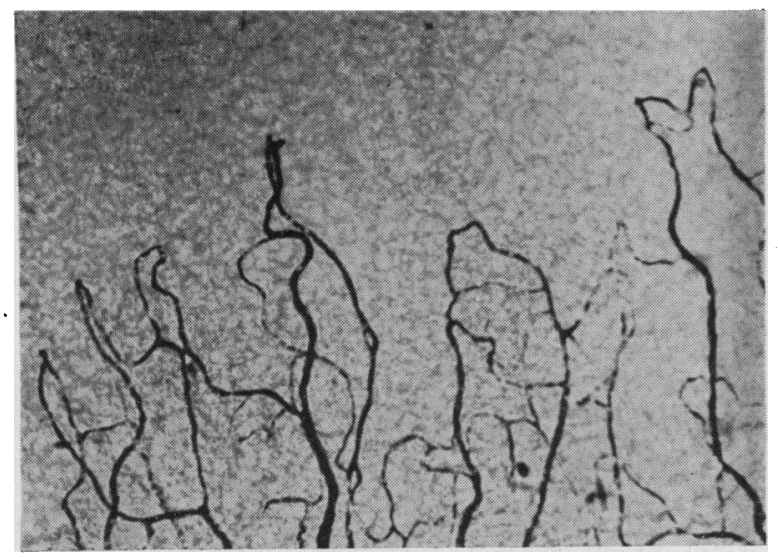

FIG. 4.-Vascular network at retinal periphery in the rabbit.

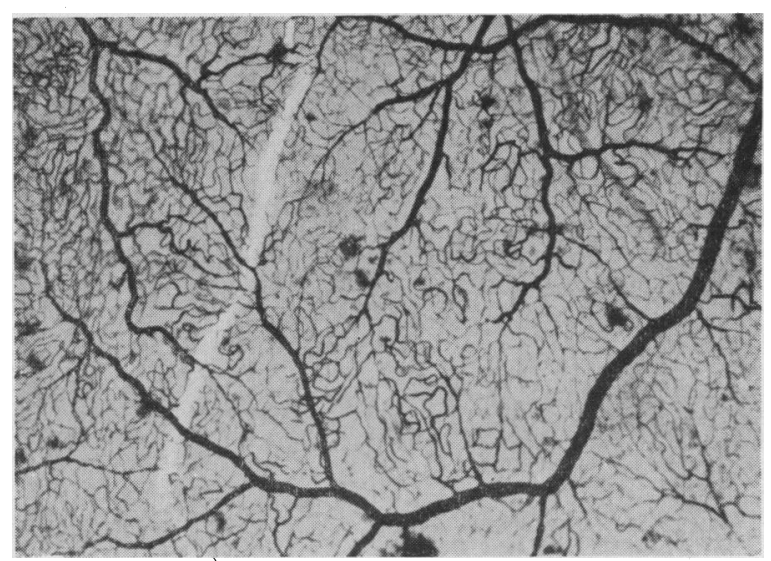

FIG. 5.-Horizontal raphé at level of paramacular region.

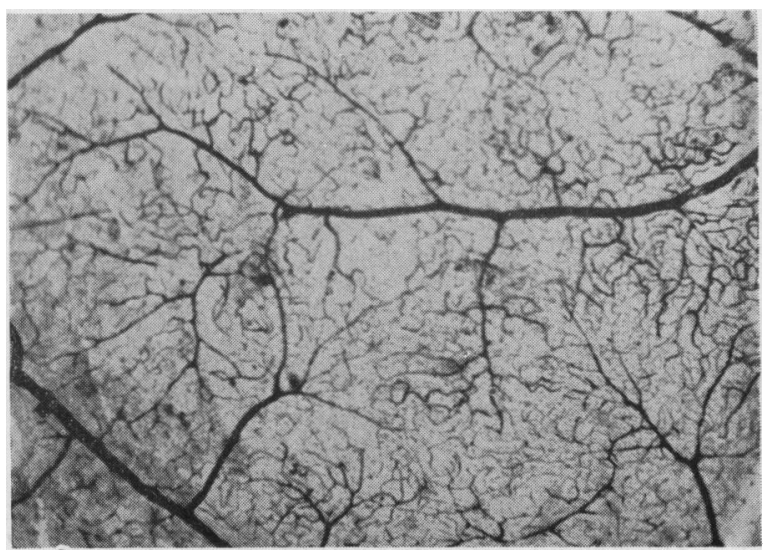

Fig. 6.-Horizontal raphé between equator and macula. 


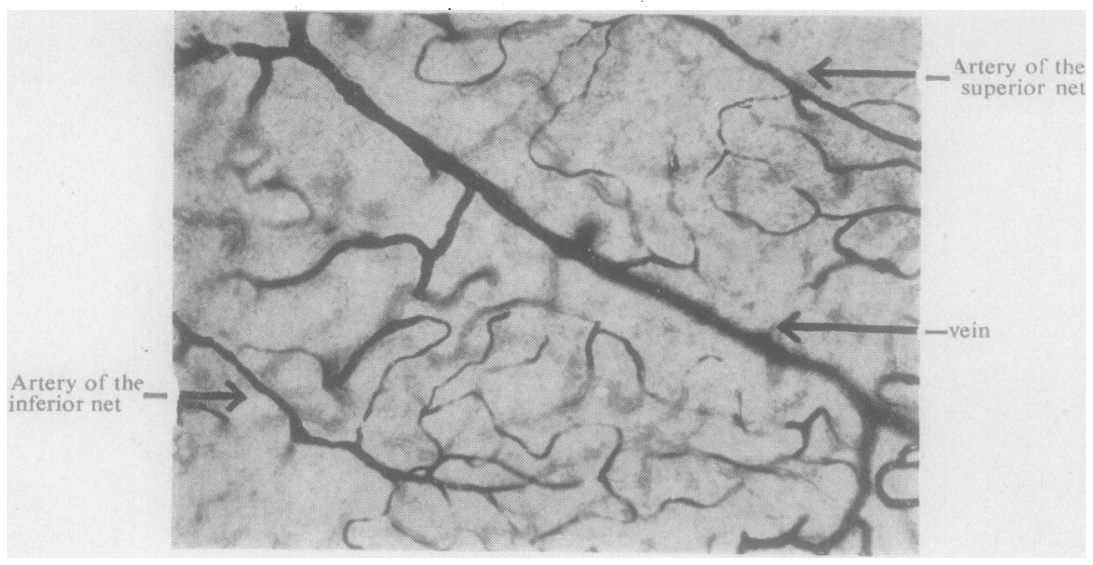

FIG. 7.-Horizontal raphé between equator and macular region.

two circulations, the superior and the inferior, anastomose intimately everywhere through a rich capillary network, which is also well marked in the paramacular region (Fig 5) as well as at the more peripheral regions (Figs 5, 6, and 7).

This last point seems to us to be very important, as it suggests that the arcuate scotomata seen in glaucoma are not angioscotomata caused by an arrest of the precapillary circulation, but are, in reality, neuroscotomata. 